\title{
O DESIGN E A PANDEMIA DA COVID-19: \\ Formas de criar sensação de bem-estar através da Semiótica aplicada em cartazes
}

\author{
Paula dos Santos Maia ${ }^{1}$
}

resumo:

O presente artigo teve por objetivo averiguar à luz da Semiótica de Pierce cartazes projetados por alunos para promover o bem-estar às pessoas em recuperação da Covid-19. A Semiótica é uma área do conhecimento que dispõe de diversos modelos de análise e veio sendo utilizada por designers, ocasionando mudanças na metodologia projetual.

Os cartazes foram desenvolvidos durante a disciplina de Semiótica aplicada ao Design, de um curso superior de Design (Imperatriz-MA), em contexto remoto, ocasionado pela pandemia. 0 processo metodológico consistiu na busca do referencial teórico por meio de uma revisão bibliográfica em obras de referência sobre os temas pesquisados. E posteriormente foram submetidos à análise semiótica. Logo, os cartazes demonstraram atingir o objetivo proposto agregando conhecimento ao ensino do Design.

palavras-chave:

Cartaz; Semiótica; Covid-19; Pandemia; Ensino de Design. 


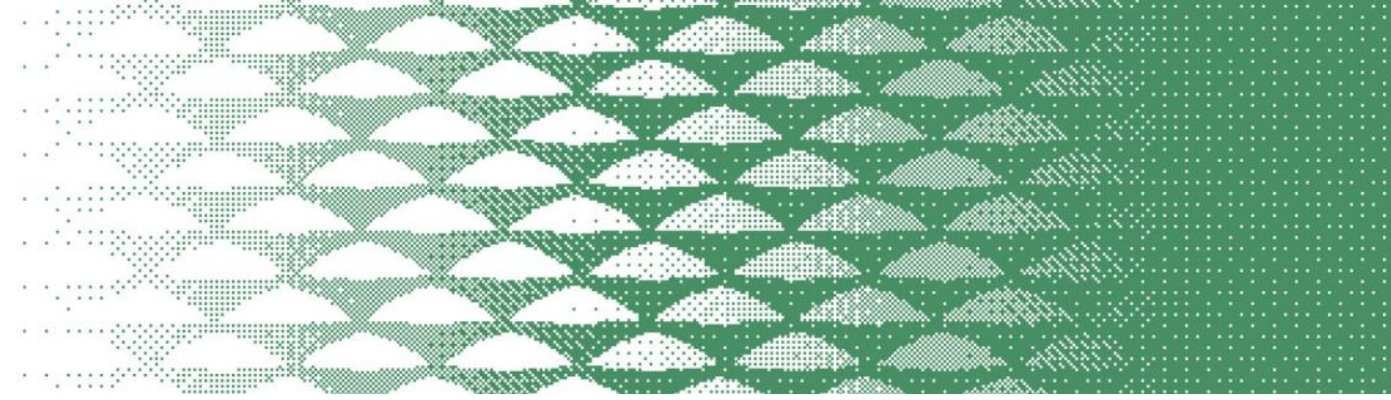

\section{Introdução}

A Organização Mundial da Saúde (OMS) declarou oficialmente, em 11 de março de 2020, a pandemia da COVID-19, e o vírus que causa essa doença respiratória, denominado coronavírus (Sars-Cov2). Sabe-se que inicialmente registraram-se casos na China e posteriormente espalharam-se por todo o mundo (OPAS - ORGANIZAÇÃO PAN-AMERICANA DA SAÚDE - OPAS /OMS, 2020). Desde então, a sociedade atual precisou rapidamente se reorganizar para enfrentar os novos e desconhecidos desafios, como do isolamento social, do trabalho remoto e das medidas de sanitização, contra o avanço da doença.

Porém, infelizmente houve um comprometimento da saúde mental da população em geral, com a difusão de mitos e informações equivocadas sobre a infecção, medidas de prevenção, bem como a dificuldade em compreender as orientações das autoridades sanitárias (BAO et. al., 2020). Ocasionando diversas sensações que não favoreceram o bem-estar. Nesse contexto foram desenvolvidos por alunos cartazes com elementos da Semiótica aplicada ao Design, para promover bem-estar às pessoas em recuperação da COVID-19 e o presente artigo objetiva averiguar à luz da Semiótica de Pierce os cartazes projetados.

\section{O Design do cartaz como mediador social}

Para Silva (2008) o cartaz teve seu início por volta do século XIX, e era utilizado para divulgação de espetáculos e casas de entretenimento nas grandes cidades. E com o passar do tempo, ele se tornou um veículo de informação e divulgação política, de serviços, de produtos e de campanhas de saúde. O cartaz é um mecanismo publicitário bastante utilizado nos países capitalistas, sendo o auxiliador e motor do consumo (MOLES, 1978).

Historicamente, o pintor francês Jules Chéret, em 1860, foi o primeiro artista plástico que elaborou cartazes sedutores para causar impacto emocional no público por meio dos estudos dos aspectos psicológicos na publicidade (ABREU, 2011). De lá para cá, o cartaz ainda carrega o registro das mudanças sociais, políticas e econômicas no decorrer do tempo, acompanhando as transformações gráficas e tecnológicas para agradar públicos, grupos e movimentos. Assim, a comunicação impulsionada pelo uso do cartaz, ainda mostra-se atrativa.

\section{1 A comunicação durante a pandemia de Covid-19}

Um estudo global divulgado pela agência de comunicação Edelman mostra que em meio à pandemia há preocupação mundial sobre fake news a respeito do Coronavírus. Porcentual de $74 \%$ dos entrevistados tem essa preocupação em relação às redes sociais - no Brasil, o medo chega a 85\% (BOUCAS, 2020). A difusão de mitos e informações equivocadas sobre a infecção agrava ainda mais o cenário (BAO et. al., 2020). E pode contribuir para condutas inapropriadas e exposição a riscos desnecessários, pois os comportamentos que as pessoas apresentam estão ligados à compreensão que têm acerca da severidade da COVID-19 (SHOJAEI e MASOUMI, 2020).

Um estudo populacional sobre implicações na saúde mental, diante da pandemia do novo coronavírus realizado na China, incluindo 1.210 participantes em 194 cidades, durante o estágio inicial da pandemia, revelou sintomas moderados a severos de ansiedade, depressão e estresse, em 28,8\%, $16,5 \%$ e $8,1 \%$ dos respondentes, respectivamente (WANG et al., 2020). Em contrapartida, receber informações precisas sobre a situação local da doença e formas de prevenção e tratamento refletiam em menores níveis de ansiedade, depressão e estresse (WANG et al., 2020). Ou seja, avessos à sensação de bem-estar. 


\section{Bem-estar, Semiótica e Design}

Para Siqueira e Padovam (2008) a concepção de saúde inclui bem-estar como um conceito chave e em decorrência, encontram-se na literatura diferentes proposições teóricas para bem-estar. Todavia, apesar dos diferentes conceitos apontados sobre bem-estar, adotou-se nesse estudo a concepção de bem-estar subjetivo (ou feliz) relacionados às emoções positivas (entusiasmo e alegria) (WATSON e CLARK, 1994). A "captação" de emoções no Design é um tema bastante debatido na área (DEMIR et al., 2009; JORDAN, 1999; DESMET, 2002 e NORMAN, 2004). Porém, em paralelo há outro elemento fortemente ligado - A Semiótica. Santaella (2007) define Semiótica como a ciência que investiga todas as linguagens possíveis com o intuito de examinar os modos de constituição de todo e qualquer fenômeno de produção de significado e sentido.

É uma área do conhecimento que dispõe de diversos modelos de análise, oferece os fundamentos teóricos e as ferramentas metodológicas para o estudo da construção dos significados (OLIVEIRA, 2007). A Semiótica veio sendo utilizada por designers em duas direções: a semiologia que se originou na linguística, de Ferdinand de Saussure (1857-1913), e a decorrente do pragmatismo americano, com Charles Sanders Peirce (1839-1914). Ambas, influenciaram em mudanças na metodologia projetual (MAGER, 2008). A partir dos anos 80, Bürdek (2006) aponta o aparecimento da expressão "linguagem do produto", surgida para confirmar que o design também se encarrega das relações homem-objeto (interesses do conhecimento) e a semiótica fomentou importantes subsídios para isso. Niemeyer (2010) diz que a importância do significado dá relevância no projeto e é um ponto de partida para entender como se dá a construção de um sistema de significação.

A Semiótica na atividade projetual do Design ocorre através de uma sistematização na qual é necessário se identificar: a) os valores centrais (personalidade e perspectivas do público); b) construir um personagem (descobrir os sentimentos do usuário a partir de seus valores); c) encontrar uma voz visual (listar palavras que expressem valores para o público). Assim, é necessário desenvolver o projeto realizando as associações com as classes sígnicas, e avaliando o fator comunicacional para conduzir a compreensão ao público (NIEMEYER, 2010). Embora seja recente a utilização da Semiótica nas grades curriculares dos cursos de graduação em Design (CARDOSO et. al., 2014). Neste estudo, optou-se por utilizar a análise da semiótica norte-americana propagada pelo cientistalógico-filósofo de Pierce como base.

\subsection{A Semiótica de Pierce}

A Semiótica de Pierce foi "concebida como lógica" e a lógica analisa qualquer fenômeno, como produtor de significação e de sentido (SANTAELLA, 2007). Assim, toda a obra de Peirce é alicerçada na ciência da fenomenologia, divida em três categorias universais aplicadas a qualquer fenômeno: Primeiridade, Secundidade e Terceiridade. O Quadro 1 expõe as relações, a seguir:

Quadro 1 - Categoria universais da Semiótica de Pierce.

\begin{tabular}{|c|c|c|c|}
\hline $\begin{array}{c}\text { Categorias do } \\
\text { signo }\end{array}$ & $\begin{array}{c}\text { Signo em } \\
\text { relação ao } \\
\text { Representâmem }\end{array}$ & $\begin{array}{c}\text { Signo em } \\
\text { relação ao objeto }\end{array}$ & $\begin{array}{c}\text { Signo em relação } \\
\text { ao interpretante }\end{array}$ \\
\hline PRIMEIRIDADE & Qualisigno & Ícone & Rema \\
\hline SECUNDIDADE & Sinsigno & Índice & Dícente \\
\hline TERCEIRIDADE & Legisigno & Símbolo & Argumento \\
\hline
\end{tabular}

Fonte: NIEMEYER (2010)

A Primeiridade é conhecida por ser a categoria da qualidade e do sentimento. São aqueles fenômenos que se apresentam sem a interferência de nenhum outro (SANTAELLA, 2007). A 


\section{JOP'21}

Secundidade é a categoria da experiência, do esforço e do fato. Trata-se da categoria de confrontação, de relação, é o ensinamento da experiência (DELEDALE, 1978). E a Terceiridade é a categoria que se caracteriza pela mediação, um terceiro relacionando o ato causal e o seu efeito. Age com força de lei, mediando e possibilitando as relações entre dois elementos (SANTAELLA, 2007).

Conforme o Quadro 1 temos que a tríade qualisigno-sinsigno-legisigno se faz a partir do aspecto manifesto do signo, pois este "em si ou Representâmen é algo que integra o processo de representação, passível de ser percebido, pelo sentido. Ele é o suporte das significações que serão extraídas do signo" (NIEMEYER, 2010, p. 39). O Objeto é constituído pelas estratégias pelas quais esse 'algo' se faz representar, é a mediação que o signo estabelece, formando a tríade ícone-índicesímbolo. Sendo que quando a representação se dá por semelhança temos um Ícone. Enquanto que, quando o procedimento de representação se faz por meio de marcas que o objeto causa, temos um Índice (NIEMEYER, 2010). Seguindo a análise do Quadro 1, sobre o Símbolo, temos que a relação se dá por um processo de convenção, sendo que "a associação não é arbitrária mas determinada por princípios pré-existentes, inerentes ao tipo de código a que pertence o signo" (NIEMEYER, 2010, p. 42). E finalmente, a tríade rema-dicente-argumento se relaciona com o interpretante, que consiste nas possibilidades interpretativas do signo (SANTAELLA, 2007; NIEMEYER, 2010).

\section{Metodologia}

Para o presente estudo, a metodologia adotada é de ordem qualitativa a mais indicada para as nossas pretensões de "focar representações de mundo, relações sociais, identidades, opiniões, atitudes, crenças ligadas a um meio social" (RESENDE, 2009, p. 57). Pois, trata-se de experiências vivenciadas pelos alunos quanto ao estudo e aplicação dos elementos da Semiótica no desenvolvimento de um cartaz.

Primeiramente, o método de pesquisa buscou o referencial teórico por meio de uma revisão bibliográfica em obras de referência sobre os temas pesquisados. Posteriormente, os cartazes projetados pelos alunos foram submetidos a uma análise tendo como base a Semiótica de Pierce.

\section{Produções dos alunos}

Seguem abaixo, os cartazes desenvolvidos com as devidas análises:

$\mathrm{Na}$ produção à esquerda (1) do aluno Emanuel Cavalcante e à direita (2) a do aluno Felipe Freitas.

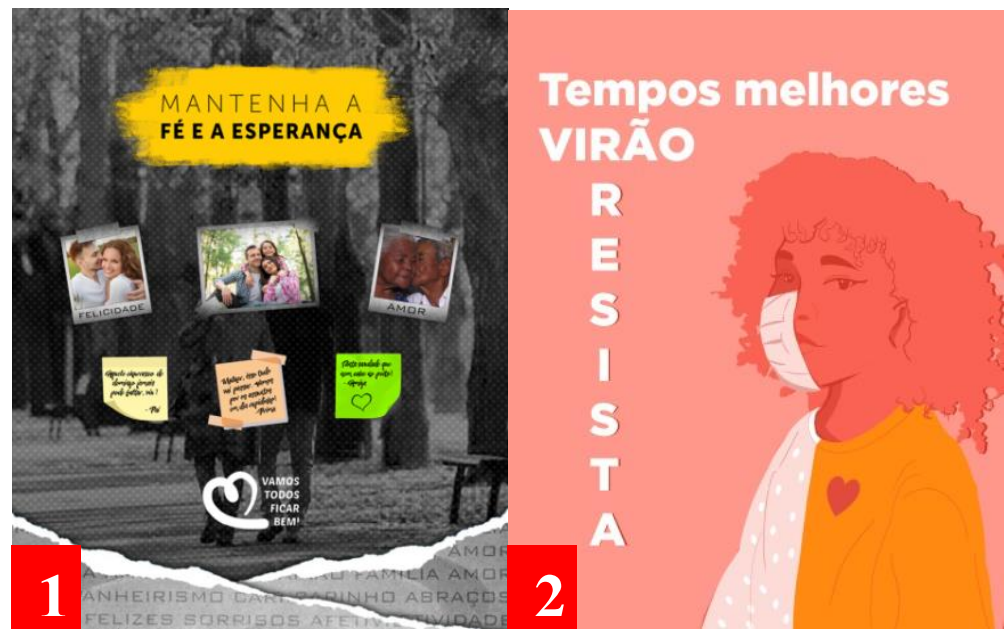

Imagem 1 - Cartazes dos alunos Emanuel Cavalcante e Felipe Freitas.

Fonte: A autora (2020) 


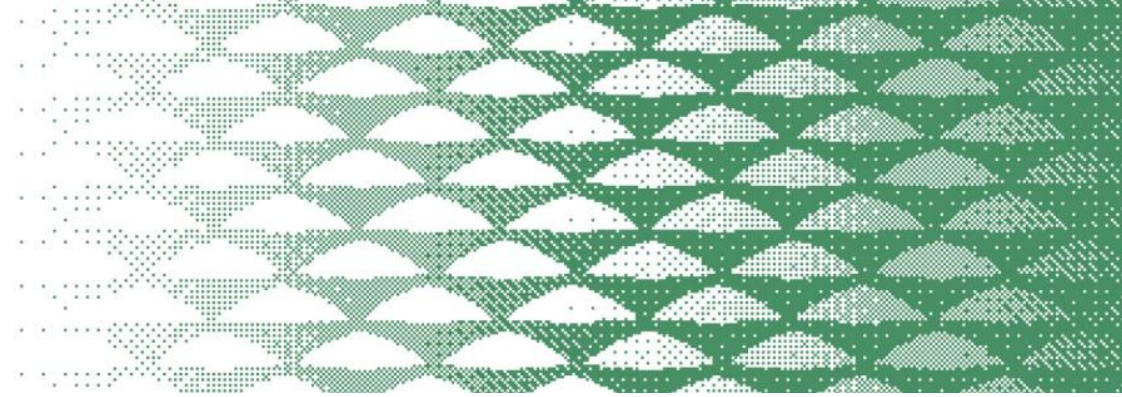

\begin{tabular}{|c|c|c|c|c|c|c|c|}
\hline & $\begin{array}{c}\text { Primeiridade } \\
\text { Representâmen } \\
\end{array}$ & $\begin{array}{c}\text { Secundidade } \\
\text { Objeto }\end{array}$ & $\begin{array}{c}\text { Terceiridade } \\
\text { Interpretante } \\
\end{array}$ & & $\begin{array}{c}\text { Primeiridade } \\
\text { Representâmen }\end{array}$ & $\begin{array}{l}\text { Secundidade } \\
\text { Objeto }\end{array}$ & $\begin{array}{l}\text { Terceiridade } \\
\text { Interpretante }\end{array}$ \\
\hline \multirow[t]{2}{*}{ Primeiridade } & \multirow{2}{*}{$\begin{array}{c}\text { Quali-Signo } \\
\text {-Sensações percebidas; } \\
\text {-Meras qualidades; } \\
\text {-Luz e Sombra; } \\
\text {-Pontos de Cor e } \\
\text { forma. }\end{array}$} & \multirow[t]{2}{*}{$\begin{array}{c}\text { İcone } \\
\text {-Relação de } \\
\text { comparação: } \\
\text { Representação da } \\
\text { figura de uma âncora. }\end{array}$} & \multirow{2}{*}{$\begin{array}{c}\text { Rema } \\
\text {-Fundo colorido; } \\
\text {-Tranquilidade; } \\
\text {-Equilibrio; } \\
\text {-Figura de uma âncora } \\
\text { e formas ao fundo. }\end{array}$} & Primeiridade & $\begin{array}{l}\text { Qepresentamen } \\
\text { Quali-Signo } \\
\text {-Sensaçóes percebidas; } \\
\text {-Meras qualidades; } \\
\text {-Luz e Sombra. }\end{array}$ & $\begin{array}{c}\text { Ícone } \\
\text {-Relaçãa de } \\
\text { comparação: A } \\
\text { fotografia da flor. }\end{array}$ & $\begin{array}{c}\text { Rema } \\
\text {-O azul; } \\
\text {-Os textos. }\end{array}$ \\
\hline & & & & \multirow[t]{2}{*}{ Secundidade } & \multirow{2}{*}{$\begin{array}{c}\text { Sin-Signo } \\
\text {-Consciência dos } \\
\text { estímulos; } \\
\text {-Sensação de liberdade. }\end{array}$} & \multirow{2}{*}{$\begin{array}{l}\text { Índice } \\
\text {-Sentir liberdade na } \\
\text { representação do } \\
\text { ambiente ao ar livre. }\end{array}$} & \multirow{2}{*}{$\begin{array}{c}\text { Dicente } \\
\text {-Uma flor que } \\
\text { propagando sementes } \\
\text { com o vento; } \\
\text {-Céu azul com nuvens. }\end{array}$} \\
\hline \multirow[t]{2}{*}{ Secundidade } & \multirow{2}{*}{$\begin{array}{c}\text { Sin-Signo } \\
\text {-Consciência dos } \\
\text { estímulos; } \\
\text {-Sensação de força e } \\
\text { resistência; } \\
\text {-Tons rosados/pastéis: } \\
\text { Aquecer. }\end{array}$} & \multirow{2}{*}{$\begin{array}{l}\text { Índice } \\
\text { - Sentir a força e a } \\
\text { resistência virã̃o na } \\
\text { representação da } \\
\text { âncora. }\end{array}$} & \multirow[t]{2}{*}{$\begin{array}{c}\text { Dicente } \\
\text {-Uma âncora "fincada" } \\
\text { em relevos do solo. }\end{array}$} & & & & \\
\hline & & & & \multirow[t]{2}{*}{ Terceiridade } & \multirow{2}{*}{$\begin{array}{c}\text { Legi-Signo } \\
\text {-Interpretação das } \\
\text { sensações; } \\
\text {-Combate a pandemia; } \\
\text {-Interposição } \\
\text { interpretativa } \\
\text { (consciência e } \\
\text { percepção). }\end{array}$} & \multirow{2}{*}{$\begin{array}{c}\text { Símbolo } \\
\text {-Frase "Fica em casa" } \\
\text { acabou também se } \\
\text { tornando um símbolo } \\
\text { desse momento; } \\
\text {-A flor que se } \\
\text { assemelha ao "Dente- } \\
\text { de-Leão" simboliza a } \\
\text { liberdade, na } \\
\text { propagação de suas } \\
\text { sementes, livremente } \\
\text { pelo vento. }\end{array}$} & \multirow{2}{*}{$\begin{array}{c}\text { Argumento } \\
\text {-A ideia dessa } \\
\text { produção produz o } \\
\text { sentido de que } \\
\text { aproveitar esse } \\
\text { momento pode ser } \\
\text { também libertador ao } \\
\text { autoconhecimento. } \\
\text { Voltar para si como } \\
\text { forma de obter } \\
\text { liberdade. }\end{array}$} \\
\hline Terceiridade & $\begin{array}{c}\text { Legi-Signo } \\
\text {-Interpretação das } \\
\text { sensações; } \\
\text {-Combate a pandemia; } \\
\text {-Interposição } \\
\text { interpretativa } \\
\text { (consciência e } \\
\text { percepção). }\end{array}$ & $\begin{array}{c}\text { Símbolo } \\
\text {-A frase formada por } \\
\text { palavras que passaram } \\
\text { por uma convenção. }\end{array}$ & $\begin{array}{c}\text { Argumento } \\
\text {-A ideia dessa } \\
\text { produção produz o } \\
\text { sentido de que na } \\
\text { pandemia precisamos } \\
\text { ser fortes e resistentes } \\
\text { como uma âncora e } \\
\text { "galgar" etapas para } \\
\text { superacão. }\end{array}$ & & & & \\
\hline
\end{tabular}

Fonte: A autora (2020).

Na produção à esquerda (5) da aluna Christiany Silva e à direita (6) a do aluno Sidecley Lima Júnior.

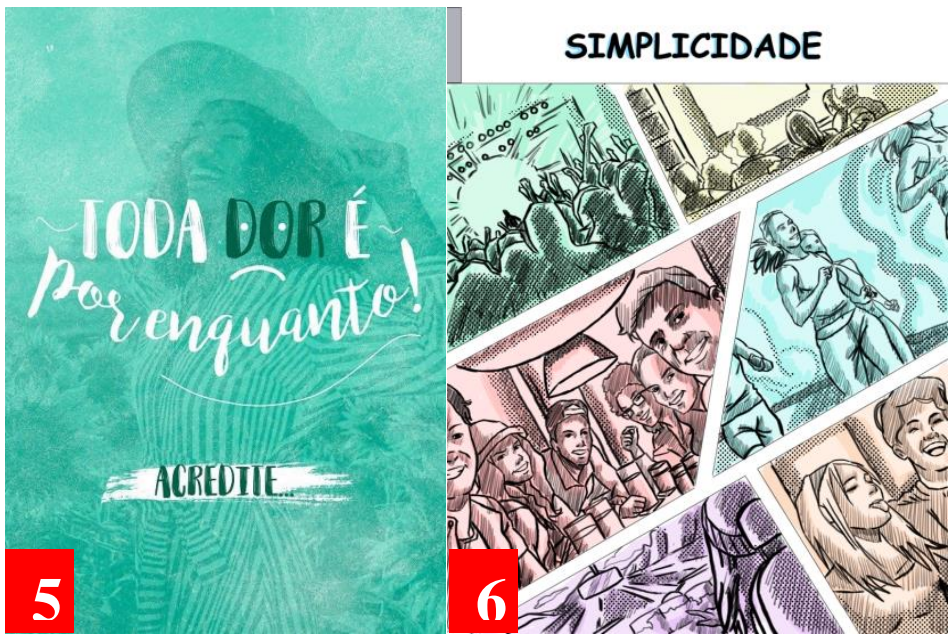

Imagem 3 - Cartazes dos alunos Christiany Silva e Sidecley Lima Júnior. Fonte: A autora (2020).

Em síntese, pode-se estabelecer a seguinte ordenação dos elementos visuais da produção em relação às categorias fenomenológicas, conforme os Quadros 6 e 7 abaixo:

Quadros 6 e 7 - Síntese do processo de construção de sentido nos cartazes 5 e 6. 


\section{JOP

\begin{tabular}{|c|c|c|c|c|c|c|c|}
\hline & $\begin{array}{c}\text { Primeiridade } \\
\text { Representâmen }\end{array}$ & $\begin{array}{l}\text { Secundidade } \\
\text { Objeto }\end{array}$ & $\begin{array}{l}\text { Terceiridade } \\
\text { Interpretante }\end{array}$ & & $\begin{array}{c}\text { Primeiridade } \\
\text { Representấmen }\end{array}$ & $\begin{array}{l}\text { Secundidade } \\
\text { Objeto }\end{array}$ & $\begin{array}{l}\text { Terceiridade } \\
\text { Interpretante }\end{array}$ \\
\hline \multirow[t]{2}{*}{ Primeiridade } & \multirow[t]{2}{*}{$\begin{array}{c}\text { Quali-Signo } \\
\text {-Sensaçốes percebidas; } \\
\text {-Meras qualidades. }\end{array}$} & \multirow{2}{*}{$\begin{array}{c}\text { İcone } \\
\text {-Relação de } \\
\text { comparação: } \mathrm{A} \\
\text { fotografia ao fundo; } \mathrm{Na} \\
\text { palavra dor a } \\
\text { representação de um } \\
\text { "carinha triste". }\end{array}$} & \multirow[t]{2}{*}{$\begin{array}{c}\text { Rema } \\
\text { - O azul; } \\
\text {-Os textos; } \\
\text {-A figura humana; } \\
\text {-Um chapéu. }\end{array}$} & Primeiridade & $\begin{array}{c}\text { Quali-Signo } \\
\text {-Sensaçốes percebidas; } \\
\text {-Meras qualidades. }\end{array}$ & $\begin{array}{c}\text { İ́one } \\
\text {-Relação de } \\
\text { comparação: As } \\
\text { ilustraçôes das pessoas } \\
\text { e objetos. }\end{array}$ & $\begin{array}{c}\text { Rema } \\
\text {-Formas; } \\
\text {-Cores; } \\
\text {-Ilustração de pessoas; } \\
\text {-Movimento e Frames. }\end{array}$ \\
\hline & & & & \multirow[t]{2}{*}{ Secundidade } & \multirow{2}{*}{$\begin{array}{c}\text { Sin-Signo } \\
\text {-Consciência dos } \\
\text { estimulos; } \\
\text {-Sensação de } \\
\text { simplicidade. }\end{array}$} & \multirow{2}{*}{$\begin{array}{c}\text { Indice } \\
\text {-Sentir a simplicidade } \\
\text { compartilhada no } \\
\text { cotidiano com as } \\
\text { pessoas. } \\
\text {-As figuras em frames } \\
\text { "cortadas" indicam que } \\
\text { há vários momentos. }\end{array}$} & \multirow{2}{*}{$\begin{array}{c}\text { Dicente } \\
\text {-Várias pessoas em } \\
\text { cenas do cotidiano } \\
\text { vivenciando de } \\
\text { maneira simples e feliz, } \\
\text { em frames de revista } \\
\text { em quadrinho. }\end{array}$} \\
\hline \multirow[t]{2}{*}{ Secundidade } & \multirow[t]{2}{*}{$\begin{array}{c}\text { Sin-Signo } \\
\text {-Consciência dos } \\
\text { estímulos; } \\
\text {-Sensação de frescor e } \\
\text { saúde. }\end{array}$} & \multirow[t]{2}{*}{$\begin{array}{c}\text { Índice } \\
\text {-Sentir frescor e saúde } \\
\text { saindo de casa, a luz do } \\
\text { sol. } \\
\text {-A própria imagem de } \\
\text { fundo indica como será } \\
\text { o futuro próximo. }\end{array}$} & \multirow[t]{2}{*}{$\begin{array}{l}\text { Dicente } \\
\text {-Uma mulher ao sol } \\
\text { segura um chapéu e } \\
\text { sorrir de olhos } \\
\text { fechados. }\end{array}$} & & & & \\
\hline & & & & \multirow[t]{2}{*}{ Terceiridade } & \multirow[b]{2}{*}{$\begin{array}{c}\text { Legi-Signo } \\
\text {-Interpretação das } \\
\text { sensações; } \\
\text {-Combate a pandemia; } \\
\text {-Interposição } \\
\text { interpretativa } \\
\text { (consciência e } \\
\text { percepção). }\end{array}$} & \multirow{2}{*}{$\begin{array}{c}\text { Símbolo } \\
\text {-Na palavra } \\
\text { "Simplicidade" que } \\
\text { passou por uma } \\
\text { convenção; } \\
\text {-Moradia, posse. }\end{array}$} & \multirow[b]{2}{*}{$\begin{array}{c}\text { Argumento } \\
\text {-A ideia dessa } \\
\text { produção produz o } \\
\text { sentido de que como } \\
\text { uma página de revista, } \\
\text { colecionamos } \\
\text { momentos simples que } \\
\text { não poderão ser } \\
\text { esquecidos e a partir } \\
\text { deles superaremos a } \\
\text { pandemia, juntos. }\end{array}$} \\
\hline Terceiridade & $\begin{array}{c}\text { Legi-Signo } \\
\text {-Interpretaçã̃o das } \\
\text { sensaçôes; } \\
\text {-Combate a pandemia; } \\
\text {-Interposição } \\
\text { interpretativa } \\
\text { (consciência e } \\
\text { percepção). }\end{array}$ & $\begin{array}{c}\text { Símbolo } \\
\text {-A frase formada por } \\
\text { palavras que passaram } \\
\text { por uma convenção; } \\
\text {-Simbologia da dor } \\
\text { com a linha do desenho } \\
\text { do sorriso arqueado } \\
\text { para baixo. }\end{array}$ & $\begin{array}{l}\text { Argumento } \\
\text {-A ideia dessa } \\
\text { produção produz o } \\
\text { sentido de que } \\
\text { acreditar que a dor na } \\
\text { pandemia é passageira, } \\
\text { fará surgir um futuro } \\
\text { sem doença, onde } \\
\text { poderá se desfrutar do }\end{array}$ & & & & \\
\hline
\end{tabular}

Fonte: A autora (2020).

Na produção à esquerda (7) da aluna Rhayssa Sá e à direita (8) a da aluna Natália Palmeira.

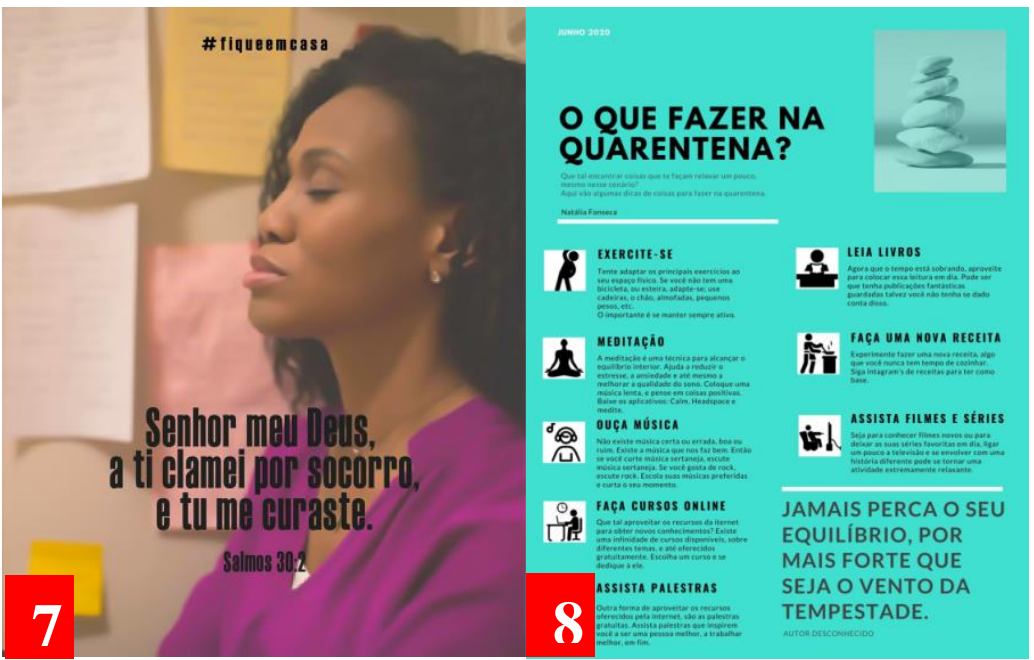

Imagem 4 - Cartazes das alunas Rhayssa Sá e Natália Palmeira.

Fonte: A autora (2020)

Em síntese, pode-se estabelecer a seguinte ordenação dos elementos visuais da produção em relação às categorias fenomenológicas, conforme os Quadro 8 e 9 abaixo:

Quadros 8 e 9 - Síntese do processo de construção de sentido nos cartazes 7 e 8. 


\begin{tabular}{|c|c|c|c|}
\hline & $\begin{array}{c}\text { Primeiridade } \\
\text { Representâmen }\end{array}$ & $\begin{array}{c}\text { Secundidade } \\
\text { Objeto }\end{array}$ & $\begin{array}{c}\text { Terceiridade } \\
\text { Interpretante }\end{array}$ \\
\hline Primeiridade & $\begin{array}{c}\text { Quali-Signo } \\
\text {-Sensaçốes percebidas; } \\
\text {-Meras qualidades. }\end{array}$ & $\begin{array}{c}\text { Ícone } \\
\text {-Relação de } \\
\text { comparação: } \mathrm{A} \\
\text { fotografia da mulher. }\end{array}$ & $\begin{array}{l}\text { Rema } \\
\text {-Os textos; } \\
\text {-A figura humana; } \\
\text {-Suave filtro. }\end{array}$ \\
\hline Secundidade & $\begin{array}{c}\text { Sin-Signo } \\
\text {-Consciência dos } \\
\text { estímulos; } \\
\text {-Sensação de calmaria } \\
\text { e paz (religião) }\end{array}$ & $\begin{array}{c}\text { Índice } \\
\text {-Sentir a paz e calmaria } \\
\text { através do contato com } \\
\text { algo "divino", além do } \\
\text { "plano fisico". } \\
\text {-A mulher de olhos } \\
\text { fechados indica que } \\
\text { está em meditação, ou } \\
\text { talvez orando (presença } \\
\text { do versiculo). }\end{array}$ & $\begin{array}{c}\text { Dicente } \\
\text {-Uma mulher de perfil } \\
\text { em pé, de olhos } \\
\text { fechados, como se } \\
\text { estivesse meditando, } \\
\text { em um ambiente de } \\
\text { trabalho. }\end{array}$ \\
\hline Terceiridade & $\begin{array}{c}\text { Legi-Signo } \\
\text { Interpretação das } \\
\text { sensações; } \\
\text {-Combate a pandemia; } \\
\text {-Interposição } \\
\text { interpretativa } \\
\text { (consciência e } \\
\text { percepção). }\end{array}$ & $\begin{array}{c}\text { Símbolo } \\
\text {-Frase "Fica em casa" } \\
\text { acabou também se } \\
\text { tornando um símbolo } \\
\text { desse momento; } \\
\text {-Nas palavras, pois, } \\
\text { passaram por uma } \\
\text { convenção. }\end{array}$ & $\begin{array}{c}\text { Argumento } \\
\text {-A ideia dessa } \\
\text { produção produz o } \\
\text { sentido de que em } \\
\text { qualquer lugar, em um } \\
\text { momento de "oração" } \\
\text { podemos acessar um } \\
\text { "divino" e obter êxito. } \\
\text { No caso, a cura para o } \\
\text { coronavirus. }\end{array}$ \\
\hline
\end{tabular}

\begin{tabular}{|c|c|c|c|}
\hline & $\begin{array}{c}\text { Primeiridade } \\
\text { Representâmen }\end{array}$ & $\begin{array}{c}\text { Secundidade } \\
\text { Objeto }\end{array}$ & $\begin{array}{c}\text { Terceiridade } \\
\text { Interpretante }\end{array}$ \\
\hline Primeiridade & $\begin{array}{c}\text { Quali-Signo } \\
\text {-Sensaçôes percebidas; } \\
\text {-Meras qualidades. }\end{array}$ & $\begin{array}{c}\text { Ícone } \\
\text {-Relação de } \\
\text { comparação: } \mathrm{A} \\
\text { fotografia das pedras, } \\
\text { os icones das práticas } \\
\text { indicadas. }\end{array}$ & $\begin{array}{c}\text { Rema } \\
\text {-Cor azul; } \\
\text {-Os textos; } \\
\text {-Vários desenhos } \\
\text { espalhados. }\end{array}$ \\
\hline Secundidade & $\begin{array}{c}\text { Sin-Signo } \\
\text {-Consciência dos } \\
\text { estímulos; } \\
\text {-Sensação equilibrio e } \\
\text { pró-atividade. }\end{array}$ & $\begin{array}{c}\text { Índice } \\
\text {-Sentir o equilibrio e a } \\
\text { pró-atividade através } \\
\text { dos elementos dos } \\
\text { icones; } \\
\text {-A disposição em lista } \\
\text { indica sequencias de } \\
\text { atividades a fazer. }\end{array}$ & $\begin{array}{c}\text { Dicente } \\
\text {-Ícones de tarefas para } \\
\text { a execução de } \\
\text { atividades; } \\
\text {-A imagem de pedras } \\
\text { sobrepostas. }\end{array}$ \\
\hline Terceiridade & $\begin{array}{c}\text { Legi-Signo } \\
\text { Interpretação das } \\
\text { sensações; } \\
\text {-Combate a pandemia; } \\
\text {-Interposição } \\
\text { interpretativa } \\
\text { (consciência e } \\
\text { percepção). }\end{array}$ & $\begin{array}{c}\text { Símbolo } \\
\text {-As pedras empilhadas } \\
\text { simbolizam a filosofia } \\
\text { Zen (Equilibrio); } \\
\text {-Nas palavras, pois, } \\
\text { passaram por uma } \\
\text { convenção. }\end{array}$ & $\begin{array}{c}\text { Argumento } \\
\text {-A ideia dessa } \\
\text { produção induz ao } \\
\text { espectador a praticar } \\
\text { atividades, seguindo } \\
\text { um manual para } \\
\text { equilibrar e dar saúde } \\
\text { durante o isolamento } \\
\text { social. }\end{array}$ \\
\hline
\end{tabular}

Fonte: A autora (2020).

\section{Considerações Finais}

A partir dos resultados podemos comprovar a importância de se trabalhar teorias a partir das produções dos alunos. Apesar de a Semiótica de Peirce ter um cunho mais filosófico, ela auxilia no trabalho da sensibilidade e da percepção dos alunos. Preliminarmente pela análise semiótica, os cartazes conseguiram promover a sensação de bem-estar conforme objetivado. Porém, futuramente é ideal que se faça um estudo sobre a percepção do público de interesse com relação aos cartazes desenvolvidos. Assim, poderemos fortificar ainda mais, as contribuições para o ensino da Semiótica aplicada ao Design.

\section{COVID-19'S DESIGN AND PANDEMIC - Ways to create a sense of well-} being through Semiotics applied to posters

Abstract: The is paper was to investigate in the light of Pierce's Semiotics posters designed by students to promote the well-being of people recovering from Covid-19. Semiotics is an area of knowledge that has several models of analysis and has been used by designers causing changes in the design methodology.

The posters were developed during the discipline of Semiotics applied to Design from a higher course in Design in the city of Imperatriz Maranhão Brazil in a remote contexto caused by the pandemic. The methodological process consisted of the search for the theoretical framework through a bibliographic review in reference works on the researched themes. And later they were subjected to semiotic analysis. Soon the posters demonstrated to reach the proposed objective adding knowledge to the teaching of Design.

Keywords: Poster; Semiotics; Covid-19; Pandemic; Design teaching. 


\section{JOP \\ DESIGN \\ de Pós-Graduaçąo em Design - UFMA}

Referências bibliográficas

ABREU, Karen Cristina Kraemer. CARTAZ PUBLICITÁRIO: UM RESGATE HISTÓRICO. Trabalho apresentado no GT de Historiografia da Mídia, integrante do VIII Encontro Nacional de História da Mídia, 2011.

BAO, Y., SUN, Y., MENG, S., SHI, J., \& LU, L. (2020). 2019-nCoV epidemic: address mental health care to empower society. The Lancet, 395(10224), e37-e38. http://dx.doi.org/10.1016/S01406736(20)30309-3.

BOUCAS, Cibelle. Valor Econômico - Audiência de TV é a maior em cinco anos. Recorde supera números da Copa do Mundo e da Olimpíada. São Paulo - Publicado em 03/04/2020. Acesso em 13/04/2020 as 12:47h - https://valor.globo.com/empresas/noticia/2020/04/03/audienciade-tveamaior-em-cinco-anos.ghtml

BÜRDEK, Bernard. História, teoria e prática do design de produtos. São Paulo: Blücher, 2006.

CARDOSO, Cilene Estol; POZZI, Marion; CURTIS, Maria do Carmo Gonçalves. CONTEXTUALIZAÇÃo HISTÓRICA DO DESIGN E ANÁLISE SEMIÓTICA: instrumentos projetuais no desenvolvimento de produtos. Blucher Design Proceedings, v. 1, n. 4, p. 803-815, 2014.

DA COSTA, Cristiano Bedin. Porque esperamos [notas sobre a docência, a obsolescência e o vírus]. Paralelo 31, v. 2, n. 15, p. 318, 2020.

DELEDALLE, Gérard. Écrits sur le signe. Paris: Éditions du Seuil, 1978.

DEMIR, E.; DESMET, P.; HEKKERT, P. 2009. Appraisal Patterns of Emotions in Human-Product Interaction. International Journal of Design, 3(2):41-51.

DESMET, P. 2002. Designing emotions. Delft, The Netherlands. Tese de Doutorado. Delft University of Technology, $225 \mathrm{p}$.

HELLER, Steven. Pop: how graphic design shapes popular culture. New York City: Allworth Press, 2010.

JORDAN, P. 1999. Pleasure with products: Human factors for body, mind and soul. In: W.S. GREEN; P.W. JORDAN (eds.), Human factors in product design: Current practice and future trends. London, Taylor \& Francis, p. 206-217.

MAGER, G. A relação entre semiótica e design. Anais do Seminário Leitura de Imagens para Educação: Múltiplas Mídias, v. 1, 2008.

MOLES, Abraham. 0 cartaz. Trad.: Miriam Garcia Mendes. São Paulo: Perspectiva/Editora da Universidade de São Paulo, 1974.

NIEMEYER, Lucy. Elementos de semiótica aplicados ao design. 4a tiragem. Rio de Janeiro, 2010. 


\section{JOP \\ DESIGN \\ de Pós-Graduaçąo em Design - UFMA}

NORMAN, D. 2004. Emotional design: Why we love (or hate) everyday things. New York, Basic

Books, $272 \mathrm{p}$.

OLIVEIRA, S. R. Moda também é texto. São Paulo: Rosari, 2007.

OPAS - ORGANIZAÇÃO PAN-AMERICANA DA SAÚDE / OMS - ORGANIZAÇÃO MUNDIAL DA SAÚDE. Folha informativa - COVID-19 (doença causada pelo novo coronavírus): principais informações. Atualizada em 07 Jul. 2020. Disponível em

https://www.paho.org/bra/index.php?option=com_content\&view=article\&id=6101:covid19\&Itemid=8 75. Acesso em: 10 jul. 2020.

RESENDE, V. M. Análise de discurso crítica e realismo crítico: implicações interdisciplinares. Campinas: Pontes editores, 2009.

RYAN, R. M. \& DECI, E. L. (2001). On happiness and human potentials: A review of research on hedonic and eudaimonic well being. Annual Review of Psychology, 52, 141-166.

SILVA, S. 2008. Cartaz e suas faces. In: S. SILVA, O design de cartazes no Cinema Marginal e na Pornochanchada. Dissertação (Mestrado em Artes e Design) - Pontifícia Universidade Católica do Rio de Janeiro, Rio de Janeiro - 2008.

SANTAELLA, L. O que é semiótica?. São Paulo: Brasileinse, 2007.

SHOJAEI, S. F., \& MASOUMI, R. (2020). The importance of mental health training for psychologists in COVID-19 outbreak. Middle East Journal of Rehabilitation and Health Studies, 7(2), e102846. http://dx.doi.org/10.5812/mejrh.102846

SIQUEIRA, Mirlene Maria Matias; PADOVAM, Valquiria Aparecida Rossi. Bases teóricas de bemestar subjetivo, bem-estar psicológico e bem-estar no trabalho. Psicologia: teoria e pesquisa, v. 24, n. 2, p. 201-209, 2008.

WANG, C., PAN, R., WAN, X., TAN, Y., XU, L., HO, C. S., \& HO, R. C. (2020). Immediate psychological responses and associated factors during the initial stage of the 2019 coronavirus disease (COVID-19) epidemic among the general population in china. International Journal of Environmental Research and Public Health, 17(5), 1729. http://dx.doi.org/10.3390/ijerph17051729.

WATSON, D., CLARK, E. \& TELLEGEN, A. (1988). Development and validation of brief measures of positive and negative affect: The PANAS scales. Journal of Personality and Social Psychology, 54, 1063-1070. 